\title{
Effects of Prenatal and Perinatal Factors on Nephrotic Syndrome Outcome
}

\author{
Parsa Yousefichaijan ${ }^{1}$, Sima Tayebi ${ }^{2}$ and Masoud Rezagholizamenjany (iD) ${ }^{2,}$ \\ ${ }^{1}$ Department of Pediatric Nephrology, School of Medicine, Amirkabir Hospital, Arak University of Medical Sciences, Arak, Iran \\ ${ }^{2}$ School of Medicine, Arak University of Medical Sciences, Arak, Iran \\ "Corresponding author: School of Medicine, Arak University of Medical Sciences, Arak, Iran. Email: masoudrezagholi074@gmail.com \\ Received 2018 December 16; Accepted 2019 October 06.
}

\begin{abstract}
Background: Nephrotic syndrome is a condition which can be influenced by pregnancy conditions.

Objectives: Based on this, aim of this study was evaluation of perinatal and prenatal indices in nephrotic syndrome.

Methods: A case control study was done in 100 children with nephrotic syndrome. Perinatal and prenatal data were obtained, and for patients' outcome determination, they had taken prednisolone for 4 weeks and syndrome types were determined based on responses to drugs as steroid responsive, steroid resistant, frequent relapse, and steroids dependent. At the end, information was entered into SPSS and analyzed.

Results: Remission type children had a better outcome (No: 25) compared to others (No: 75) have a better status in prenatal and perinatal factors $(\mathrm{P}<0.05)$. Gestational age $(\mathrm{P}$ value $=0.387)$, delivery type, diabetic nephropathy $(\mathrm{P}$ value $=0.007)$, passive smoking and neonatal jaundice have significant differences in groups.

Conclusions: Some of these factors have a significant effect in nephrotic syndrome outcomes that evaluated in this study.
\end{abstract}

Keywords: Nephrotic Syndrome, Prenatal, Perinatal

\section{Background}

Nephrotic syndrome is a glomerular disease in medicine and urology defined with increased glomerular permeability, because of normal glomerular alterations in basement membrane barrier and cells, large amounts of protein are excreted into urine (1). Since protein excretion into urine in healthy kidneys are low $\left(<4 \mathrm{mg} / \mathrm{m}^{2} / \mathrm{h}\right.$ or $\mathrm{UPr} / \mathrm{Cr}<0.2)$ but in nephrotic syndrome, excretion of protein in urine is increases and reaches more than 40 $\mathrm{mg} / \mathrm{m}^{2} / \mathrm{h}$ or $\mathrm{UPr} / \mathrm{Cr}>2.0$ (2). In addition, prenatal (before birth) and perinatal (the period around childbirth, especially the 20th weeks of gestation to the 28th day of newborn life) factors in children and mothers can influence incidence and prognosis of congenital diseases $(3,4)$, in following we included some of these factors.

Prenatal history including:

- Exposure to medication (development toxin (e.g., phenytoin); may be an index of care giving risk),

- Injuries, hyperthermia (damage to CNS),

- Alcohol ingestion (fetal alcohol syndrome; index of care giving risk),

- Maternal illness (so-called "TORCH" infections) (Toxoplasmosis, Syphilis, Rubella, Cytomegalovirus, HSV infec- tions),

- Smoking (possible CNS damage),

- Radiation exposure (damage to CNS),

- HIV exposure (congenital HIV infection),

- Nutrition (inadequate fetal nutrition),

- Prenatal care (index of social status).

In addition, perinatal history including:

- Specific perinatal adverse events (increased risk of CNS damage),

- APGAR scores (hypoxia, cardiovascular impairment),

- Labor and delivery (hypoxia or index of abnormal prenatal development).

\section{Objectives}

Based on high prevalence and complications of NS, also probably efficacy of prenatal and perinatal factors on it, the purpose of this study was to investigate prenatal and perinatal factors in NS outcomes. 


\section{Methods}

\subsection{Study Setting}

In a case series study, referred to Amir-Kabir Hospital at $2015-2016$

\subsection{Study Population}

In total, we selected 100 children younger than 15 years old of age with NS by convenience sampling. Inclusion criteria included participant's consent to research and absence of another congenital kidney disease and exclusion criteria were severe liver, kidney, or cardiac disease, no consent to use their data in the study. Based on patient outcomes and steroid responses we divided them into four groups as steroid resistant, steroid responsive, steroid dependent, and frequent relapse.

\subsection{Statistical Analysis}

We used chi-square test in SPSS software and P value $<$ 0.05 was considered as significance value.

\subsection{Ethical Considerations}

Ethical issues (data fabrication, including plagiarism, double publication) have been completely observed by the authors. In addition, the Ethical Committee of Arak University of Medical Sciences confirmed the study protocol.

\subsection{Measurements}

Researchers have assessed prenatal and perinatal factors in patients obtained by patient interview on admission to hospital.

\section{Results}

Based on perinatal factors, based on Table 1 , all of them including gestational age $(\mathrm{P}=0.001)$, delivery type $(\mathrm{P}=$ $0.001)$ and maternal age in delivery (Yrs.) $(\mathrm{P}=0.04)$ in remission group have significantly better status.

Nevertheless, regarding prenatal factors, based on Table 2 , factors including economic conditions $(\mathrm{P}=0.001)$, preeclampsia (0.04), consanguineous marriage $(\mathrm{P}=0.001)$, gestational HTN $(\mathrm{P}=0.001)$, mothers' passive smoking $(\mathrm{P}=$ $0.001)$ and neonatal jaundice $(\mathrm{P}=0.07)$ were significantly better in remission group, since other factors in remission group were better but not statistically significant.

\section{Discussion}

In our study, prenatal and perinatal factors in nephrotic syndrome were assessed and these reviews are seen in a few of other studies. Nevertheless, in other studies that have investigated these aspects, two factors have not been investigated in one article so the most relevant articles will be discussed and compared with our findings in the following.

Regarding nephrotic syndrome, we have expressed the most relevant studies. In a study about Finnish type, by Huttunen, they observed an increase in BUN or Cr levels in 14 cases and more than 50\% of the children died before 6 months, but in none a frank uremia developed before death. In the children who died, $43 \%$ no cause of death rather than congenital nephrotic syndrome may be showed but infection appeared to be the immediate cause of death in $31 \%$ of the cases. Thrombi in large vessels were found in 11 out of 58 necropsies (5). In another study by Chanchlani and Parekh about ethnic differences in NS reported that, incidence and response to treatment in nephrotic syndrome varies by ethnicity (6). In a study by Takahashi et al. which was about triggers of relapse in steroid-dependent children, they observed that 442 relapses occurred in 2499 patients (7). Also in a study by Kerlin, it was observed that incidence of thromboembolism in childhood with nephrotic syndrome was higher than healthy children so children with NS should be followed for TE (8). However, in our study this criterion was not followed. Also in another study which was conducted by Abu Saad and Awadalla it was observed that most of the studied children had low levels of self-care (9). In another study which was about attention deficit hyperactivity disorder in steroid-dependent nephrotic syndrome and conducted by Yousefichaijan et al., no significant relationship between different types of ADHD in children with SDNS and the control group was observed (10). Another study, by Sreenivasa et al., observed that UTI is a common infection accompanying NS, also a high index of suspicion and early institution of appropriate antibiotics will help in attenuating morbidity and mortality (11). Wen investigates the difference in serum proteomes of SSNS and SRNS patients and this who serum proteins may be a useful predictor for the efficacy of steroid therapy, who find a positive response to the study. In a study by Feehally et al., it was concluded from analysis of results that NS was more common in Asian children living in the city of Leicester in, and there was an unusually low incidence of NS in non-Asian children living in the city (12).

In a study by Vasconcelos et al. in 2016, they observed that associated risk factors might induce the OCD expression such as pregnancy edema and labor that are prolonged. Rossaint and Zarbock in a study in 2016 showed that sepsis, nephrotoxic drugs and major surgery, as major 


\begin{tabular}{|c|c|c|c|c|c|}
\hline Variables & Steroid Responsive & Steroid Dependent & Steroid Resistant & Frequent Relapse & PValue \\
\hline Gestational age & & & & & $<0.001$ \\
\hline Term & 77 & 39 & 25 & 20 & \\
\hline Preterm & 13 & 49 & 73 & 80 & \\
\hline Postterm & 12 & 12 & 0 & 0 & \\
\hline Delivery type & & & & & $<0.001$ \\
\hline Natural delivery & 64 & 76 & 52 & 72 & \\
\hline Cesarean section & 36 & 24 & 48 & 28 & \\
\hline Maternal age in delivery, $y$ & & & & & 0.04 \\
\hline$<18$ & 0 & 0 & 4 & 4 & \\
\hline $18-24$ & 44 & 4 & 4 & 12 & \\
\hline $25-29$ & 48 & 28 & 12 & 0 & \\
\hline $30-34$ & 8 & 52 & 44 & 32 & \\
\hline 35 & 0 & 16 & 36 & 52 & \\
\hline
\end{tabular}

causes of acute kidney injury (AKI) in patients, and is associated with increased risk for sustained CKD (13). In a study conducted by Lei et al., it was observed that AKI is common in severely ill patients and associated with poor outcomes and high mortality rates and the stage of AKI was related with in-hospital outcomes of the patients (14). Nevertheless, in our study, many of the factors were evaluated.

\subsection{Conclusions}

Prenatal and perinatal factors in remission group were better, which showed efficacy of these factors on NS. So based on this probably we can reduce this syndrome by control of maternal factors.

\section{Acknowledgments}

For financial support, we acknowledge to the Arak University of Medical Sciences (Grant Number: 2700).

\section{Footnotes}

Authors' Contribution: All authors were equal in preparation and submission of manuscript.

Conflict of Interests: The authors declared no competing interests.

Ethical Approval: Ethical issues (data fabrication, including plagiarism, double publication) have been completely observed by the authors. In addition, the Ethical Committee of Arak University of Medical Sciences confirmed the study protocol.

Funding/Support: Our study was funded by Arak University of Medical Sciences.

\section{References}

1. Bennett MR, Pordal A, Haffner C, Pleasant L, Ma Q, Devarajan P. Urinary vitamin D-binding protein as a biomarker of steroidresistant nephrotic syndrome. Biomark Insights. 2016;11:1-6. doi: 10.4137/BMI.S31633. [PubMed: 26792978]. [PubMed Central: PMC4712977].

Nephro-Urol Mon. 2019; 11(4):e87717.
2. Hinchey J, Chaves C, Appignani B, Breen J, Pao L, Wang A, et al. A reversible posterior leukoencephalopathy syndrome. $N$ Engl J Med. 1996;334(8):494-500. doi: 10.1056/NEJM199602223340803. [PubMed: 8559202]

3. Al-Azzawi HF, Obi OC, Safi J, Song M. Nephrotic syndrome-induced thromboembolism in adults. Int J Crit Illn Inj Sci. 2016;6(2):85-8. doi: 10.4103/2229-5151.183019. [PubMed: 27308257]. [PubMed Central: PMC4901833]

4. Wong E, Lasica M, He SZ, Bajel A, Roberts AW, Mason KD, et al. Nephrotic syndrome as a complication of chronic graft-versus-host disease after allogeneic haemopoietic stem cell transplantation. Intern Med J.2016;46(6):737-41. doi:10.1111/imj.13098. [PubMed: 27257151].

5. Huttunen NP. Congenital nephrotic syndrome of Finnish type. Study of 75 patients. Arch Dis Child.1976;51(5):344-8. doi: 10.1136/adc.51.5.344. [PubMed: 938078]. [PubMed Central: PMC1545982].

6. Chanchlani R, Parekh RS. Ethnic differences in childhood nephrotic syndrome. Front Pediatr. 2016;4:39. doi: 10.3389/fped.2016.00039. [PubMed: 27148508]. [PubMed Central: PMC4835686].

7. Takahashi S, Wada N, Murakami H, Funaki S, Inagaki T, Harada K, et al. Triggers of relapse in steroid-dependent and frequently relapsing nephrotic syndrome. Pediatr Nephrol. 2007;22(2):232-6. doi: 10.1007/s00467-006-0316-y. [PubMed: 17043884].

8. Kerlin BA, Haworth K, Smoyer WE. Venous thromboembolism in pediatric nephrotic syndrome. Pediatr Nephrol. 2014;29(6):989-97. doi: 10.1007/s00467-013-2525-5. [PubMed: 23812352]. [PubMed Central: PMC6556227].

9. Abu Saad FE, Awadalla NJ. Self - care practices of school age children with nephrotic syndrome. J High Institute Public Health. 2009;39(4):709-28. doi: 10.21608/jhiph.2009.20862.

10. Yousefichaijan P, Salehi B, Rafiei M, Dahmardnezhad M, Naziri M. The correlation between attention deficit hyperactivity disorder and steroid-dependent nephrotic syndrome. Saudi J Kidney Dis Transpl. 2015;26(6):1205-9. doi: 10.4103/1319-2442.168624. [PubMed: 26586060].

11. Sreenivasa B, Murthy CS, Raghavendra K, Basavanthappa S, Pejaver R, Jadala HV. Urinary tract infection at presentation of nephrotic syndrome: A clinical evaluation. Indian J Child Health. 2015;2(1):1-4.

12. Feehally J, Kendell NP, Swift PG, Walls J. High incidence of minimal change nephrotic syndrome in Asians. Arch Dis Child.1985;60(11):101820. doi: 10.1136/adc.60.11.1018. [PubMed: 4073934]. [PubMed Central: PMC1777627].

13. Rossaint J, Zarbock A. Acute kidney injury: Definition, diagnosis and epidemiology. Minerva Urol Nefrol. 2016;68(1):49-57. [PubMed: 26364570].

14. Lei Y, Nie S, Sun DH, Bin W, Xu X. [Epidemiology of acute kidney injury in Chinese critical patients]. Nan Fang Yi Ke Da Xue Xue Bao. 2016;36(6):744-50. Chinese. [PubMed: 27320872]. 


\begin{tabular}{|c|c|c|c|c|c|}
\hline Variables & Steroid Responsive & Steroid Dependent & Steroid Resistant & Frequent Relapse & P Value \\
\hline Mother occupation & & & & & 0.064 \\
\hline Self employed & 0 & 0 & 8 & 32 & \\
\hline Worker & 16 & 12 & 32 & 12 & \\
\hline Employee & 64 & 60 & 44 & 44 & \\
\hline Mother education & & & & & 0.194 \\
\hline Under diploma & 0 & 8 & 32 & 12 & \\
\hline Diploma & 28 & 32 & 28 & 28 & \\
\hline Associate degree & 8 & 8 & 4 & 0 & \\
\hline Bachelor & 44 & 36 & 32 & 36 & \\
\hline Master's degree and higher & 20 & 16 & 4 & 24 & \\
\hline$>10$ million IRR & 12 & 0 & 4 & 8 & \\
\hline 10 - 20 million IRR & 0 & 24 & 28 & 12 & \\
\hline$>20$ million IRR & 88 & 76 & 68 & 80 & \\
\hline Maternal BMI & & & & & 0.011 \\
\hline Overweight & 16 & 8 & 20 & 16 & \\
\hline Normal & 68 & 44 & 20 & 32 & \\
\hline Underweight & 12 & 4 & 12 & 12 & \\
\hline Preeclampsia & & & & & 0.004 \\
\hline Positive & 4 & 44 & 52 & 52 & \\
\hline Negative & 96 & 56 & 48 & 48 & \\
\hline Eclampsia & & & & & 0.432 \\
\hline Positive & 12 & 0 & 4 & 4 & \\
\hline Negative & 88 & 100 & 96 & 96 & \\
\hline Diabetes & & & & & 0.118 \\
\hline Without DM & 68 & 52 & 24 & 48 & \\
\hline Gestational HTN & & & & & 0.001 \\
\hline Positive & 8 & 32 & 76 & 68 & \\
\hline Negative & 92 & 68 & 24 & 32 & \\
\hline Consanguineous marriage & & & & & 0.001 \\
\hline Positive & 12 & 40 & 76 & 72 & \\
\hline Negative & 88 & 60 & 24 & 28 & \\
\hline Mothers passive smoking & & & & & 0.001 \\
\hline Positive & 20 & 52 & 80 & 72 & \\
\hline Negative & 80 & 48 & 20 & 28 & \\
\hline Neonatal jaundice & & & & & 0.007 \\
\hline Positive & 16 & 40 & 64 & 36 & \\
\hline Negative & 84 & 60 & 36 & 64 & \\
\hline Prenatal care & & & & & 0.589 \\
\hline Inadequate & 0 & 4 & 12 & 16 & \\
\hline Average & 12 & 12 & 12 & 12 & \\
\hline Enough & 84 & 84 & 72 & 72 & \\
\hline Intense & 4 & 0 & 4 & 0 & \\
\hline
\end{tabular}

